\title{
DESAIN DAN IMPLEMENTASI PENAIK TEGANGAN MENGGUNAKAN KOMBINASI KY CONVERTER DAN BUCK- BOOST CONVERTER
}

\author{
Bustanul Arifin, Heri Suryoatmojo, Soedibjo \\ Jurusan Teknik Elektro, Fakultas Teknologi Industri, Institut Teknologi Sepuluh Nopember (ITS) \\ Jl. Arief Rahman Hakim, Surabaya 60111 Indonesia \\ e-mail: suryomgt@ee.its.ac.id ; soedieb@ee.its.ac.id
}

\begin{abstract}
Abstrak - Dewasa ini pengembangan, kebutuhan akan sumber energi terbarukan, dan penggunaan energi terbarukan (renewable energy) semakin menjadi hal yang sangat penting. Karena energi terbarukan dapat digunakan sebagai sumber energi yang digunakan untuk membangkitkan sistem pembangkit tersebar dan pembantu energi utama. Salah satu energi yang terbarukan yang digunakan untuk sistem pembangkitan adalah energi dari sinar matahari. Namun ketika intensitas cahaya matahari yang berubah-ubah mengakibatkan arus DC yang keluar dari solar sel berubah ubah, oleh karena itu dibutuhkannya suatu perangkat teknologi yang mampu menaikkan tegangan jika intensitas cahaya matahari menurun yaitu menggunakan konverter DC-DC. Pada penelitian ini didesain dan diimplementasikan topologi konverter DC-DC kombinasi konverter KY dan konverter buck-boost yang digunakan untuk menaikkan tegangan DC yang dikeluarkan panel solar sel. Hasil implementasi menunjukkan konverter dapat bekerja dengan respon waktu pensaklaran yang cepat. Selaitu konverter dapat bekerja pada rentang tegangan masukkan yang berbeda dan memiliki rasio konversi tegangan masukan yang hingga 7,16 kali dengan efisiensi $81,18 \%$ pada daya beban $90 \%$.
\end{abstract}

Kata Kunci- Solar sel, Kombinasi Konverter KY dan konverter Buck-Boost, Konverter DC - DC.

\section{PENDAHULUAN}

$\mathrm{E}$ NERGI surya merupakan sumber energi terbarukan yang tidak mencemari. Industri panel surya di dunia telah meningkat lebih dari $31 \%$ per tahun lebih bertahan dekade terakhir. Panel surya sebagai sumber terbarukan karena memiliki kelebihan, seperti tidak adanya biaya bahan bakar, sedikit perawatan, tidak ada suara, dan tidak adanya bagian yang bergerak. Namun efisiensi konversi energi aktual modul PV agak rendah dan dipengaruhi oleh kondisi cuaca dan beban yang digunakan[1]-[2].

Untuk memperoleh keluaran yang efisien diperlukan rangkaian konverter DC-DC. Konverter DC-DC berfungsi untuk menaikkan dan menurunkan tegangan Direct Current (DC), sama halnya dengan trafo yang mengubah tegangan $\mathrm{AC}$ tertentu ke tegangan DC yang lebih tinggi atau lebih rendah. Akan tetapi konverter DC-DC mempunyai efisiensi lebih tinggi dibandingkan dengan power supply konvensional karena tidak ada peningkatan ataupun pengurangan daya masukan selama pengkonversian bentuk energi listriknya[3].
Ada beberapa macam topologi pada konverter DC-DC, seperti konverter Boost dan konverter buck-boost, kelemahan tegangan konverter tersebut tidak cukup tinggi. Hingga kini, banyak macam teknik yang digunakan untuk menaikkan tegangan telah disajikan, termasuk beberapa induktor yang terhubung dalam seri dengan kapasitor, inductor dengan perbedaan rasio, superposisi tegangan berdasarkan peralihan kapasitor, transformator tambahan dengan rasio konversi sehingga meningkatkan kompleksitas konverter, dan selain itu juga komponen yang digunakan dalam pembuatan konverter masih banyak [4].

Dari macam teknik peningkatan diatas, sehingga dibutuhkan konverter yang memiliki jumlah komponen yang sedikit dan dapat menghasilkan tegangan keluaran tegangan yang lebih tinggi. Oleh karena itu, kombinasi konverter KY dengan konverter buck-boost adalah konverter yang mempunyai jumlah komponen yang sedikit dan merupakan hasil kombinasi antara konverter KY dengan konverter buckboost yang menambahkan kopel induktor. Konverter ini dapat menghasilkan perubahan tegangan yang lebih tinggi dari pada konverter pada umumnya[4].

\section{URAIAN PENELITIAN}

\section{A. Topologi kombinasi KY dan konverter Buck-Boost}

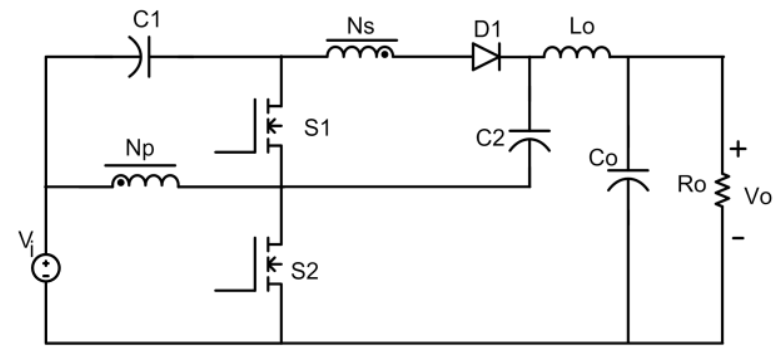

Gambar 1. Rangkaian Konverter Kombinasi KY converter dan Buck-Boost converter.

Konverter DC-DC kombinasi KY converter dan Buck-boost converter adalah konverter yang dapat meningkatkan tegangan masukkan DC ke level tegangan keluaran yang lebih tinggi. Konverter ini merupakan pengembangan dari konverter KY[4]. Gambar 1 merupakan rangkaian dari kombinasi KY converter dan buck-boost converter. 


\section{B. Mode Operasi}

\section{Coupling Sama Dengan Satu}

Mode 1 Pada saat $\mathrm{t}_{0}-\mathrm{t}_{1}$, saklar S1 on dan S2 off ditunjukan pada Gambar 2. Sumber $D C V_{\text {in }}$ menyalurkan energi ke induktor $\mathrm{L}_{\mathrm{Np}}$ dan $\mathrm{L}_{\mathrm{m}}$ kemudian ke $\mathrm{S} 2$. Dalam waktu yang bersamaan sumber $\mathrm{V}_{\text {in }}$ mengalir ke kapasitor $\mathrm{C}_{1}$, Induktor $\mathrm{L}_{\mathrm{NS}}$, dioda $\mathrm{D}_{1}$, dan saklar $\mathrm{S} 2$. Pada saat yang sama, sumber $\mathrm{V}_{\mathrm{in}}$, kapasitor $C_{1}$, Induktor $L_{N S}$, dioda $D_{1}$ terbung seri untuk menyalurkan energi ke induktor $\mathrm{L}_{0}$, kapasitor $\mathrm{C}_{\mathrm{o}}$, dan beban $\mathrm{R}$. Ketika sumber DC mengalir melalui Lm maka membuat Lm menjadi termagnetisasi dan $\mathrm{L}_{\mathrm{Ns}}$ menjadi terinduksi. Kapasitor C1 melepas energi ke induktor $L_{N s}$ dan Dioda $D_{1}$ menjadi bias maju. Pada saat yang sama, kapasitor $\mathrm{C}_{2}$ melakukan pengisian sehingga tegangan pada $\mathrm{C}_{2}$ termuati. Dalam waktu yang bersamaan, tegangan melewati $\mathrm{L}_{\mathrm{o}}$ menjadi bermuatan negatif karena $\mathrm{V}_{\mathrm{C} 2}-\mathrm{V}_{\mathrm{o}}$, kemudian membuat $\mathrm{L}_{\mathrm{o}}$ menjadi termagnetisasi.

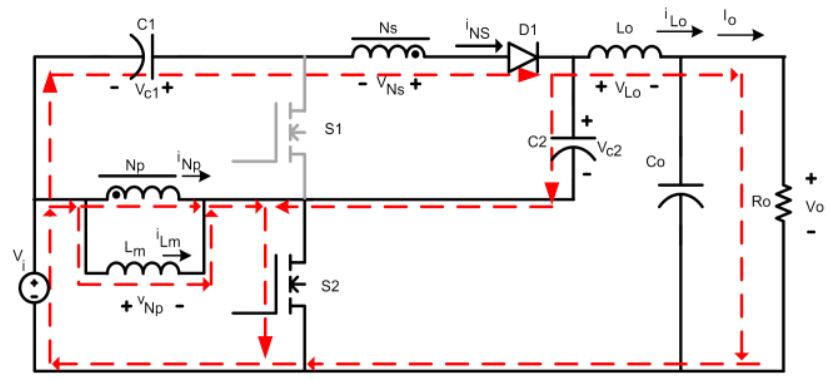

Gambar 2. Mode Operasi 1( $\left.\mathrm{t}_{0}-\mathrm{t}_{1}\right)$

Model 2 Pada saat $\mathrm{t}_{1}-\mathrm{t}_{2}$, saklar S1 on dan S2 off ditunjukan pada Gambar 3. Sumber DC Vin menyalurkan energi ke induktor kopel $\mathrm{L}_{\mathrm{Np}}$ dan $\mathrm{L}_{\mathrm{m}}$ ke $\mathrm{S} 1$ kemudian ke $\mathrm{C}_{1}$, sehingga tegangan pada $C_{1}$ menjadi $-V_{c 1}$ dan kembali ke $\mathrm{VL}_{\mathrm{Np}}$. Pada saat yang sama tegangan $\mathrm{V}_{\mathrm{in}}$, induktor $\mathrm{L}_{\mathrm{m}}$ dan $\mathrm{L}_{\mathrm{Np}}$, kapasitor $\mathrm{C}_{2}$ terhubung seri untuk menyalurkan energi ke induktor $\mathrm{L}_{\mathrm{o}}$, kapasitor $\mathrm{C}_{\mathrm{o}}$, dan beban $\mathrm{R}$. Karena tegangan seri melewati $\mathrm{C}_{2}$ maka membuat dioda $D_{1}$ menjadi terbias mundur dan $\mathrm{VL}_{\mathrm{Ns}}$ tidak teraliri tegangan, sehingga membuat tegangan pada Lo menjadi bernilai positif.

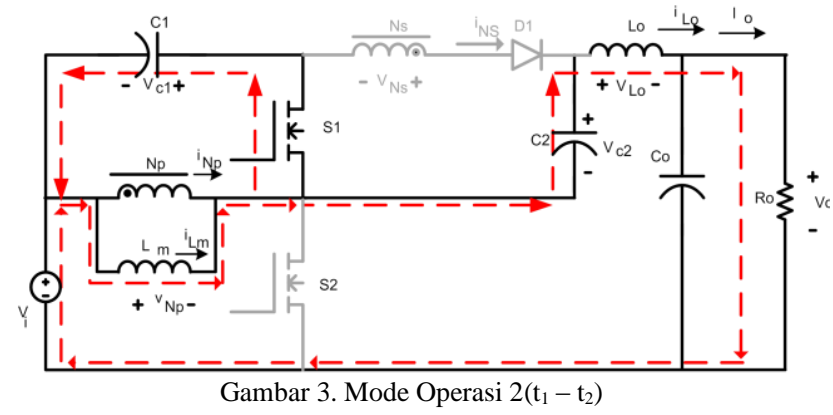

2. Coupling Tidak Sama Dengan Satu

Pada bagian ini kopling koefisien $\mathrm{k}$ adalah tidak sama satu, dengan kata lain kebocoran induktor pada couple induktor dimasukkan kedalam perhitungan.

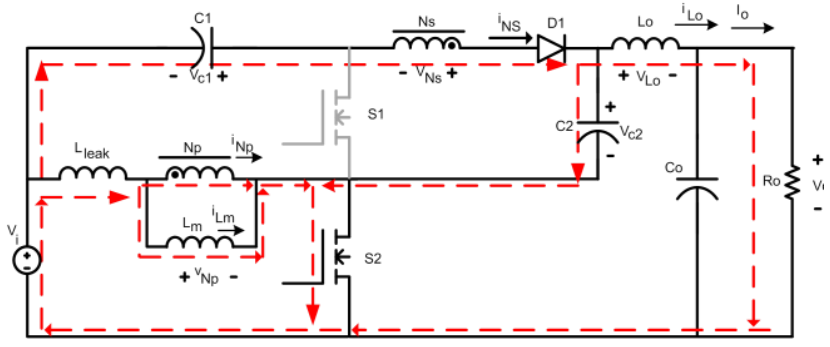

Gambar 4. Mode 1 Operasi 1 $\left(\mathrm{t}_{0}-\mathrm{t}_{1}\right)$

Mode 1 pada saat $\mathrm{t}_{0}-\mathrm{t}_{1}$, saklar S1 on dan S2 off ditunjukan pada Gambar 4. Sumber $D C V_{\text {in }}$ menyalurkan energi ke induktor $\mathrm{L}_{\mathrm{Np}}, \mathrm{L}_{\mathrm{lk}}$ dan $\mathrm{L} m$ kemudian ke S2. Dalam waktu yang bersamaan sumber $\mathrm{V}_{\text {in }}$ mengalir ke kapasitor $\mathrm{C}_{1}$, Induktor $\mathrm{L}_{\mathrm{NS}}$, dioda $D_{1}$, dan saklar $S 2$. Pada saat yang sama, sumber $V_{\text {in }}$, kapasitor $\mathrm{C}_{1}$, Induktor $\mathrm{L}_{\mathrm{Ns}}$, dioda $\mathrm{D}_{1}$ terbung seri untuk menyalurkan energi ke induktor $\mathrm{L}_{\mathrm{o}}$, kapasitor $\mathrm{C}_{\mathrm{o}}$, dan beban $\mathrm{R}$. Ketika sumber DC mengalir melalui $\mathrm{L}_{\mathrm{m}}$ dan $\mathrm{L}_{\mathrm{lk}}$ maka membuat $\mathrm{L}_{\mathrm{m}}$ dan $\mathrm{L}_{\mathrm{lk}}$ menjadi termagnetisasi dan $\mathrm{L}_{\mathrm{Ns}}$ menjadi terinduksi. Kapasitor $\mathrm{C}_{1}$ melepas energi ke induktor $\mathrm{L}_{\mathrm{Ns}}$ dan Dioda $\mathrm{D}_{1}$ menjadi bias maju. Pada saat yang sama, kapasitor $\mathrm{C}_{2}$ melakukan pengisian sehingga tegangan pada $\mathrm{C}_{2}$ termuati. Dalam waktu yang bersamaan, tegangan melewati $\mathrm{L}_{\mathrm{o}}$ menjadi bermuatan negatif karena $\mathrm{V}_{\mathrm{C}_{2}}-\mathrm{V}_{\mathrm{o}}$, kemudian membuat $\mathrm{L}_{\mathrm{o}}$ menjadi termagnetisasi.

Mode 2 pada saat $\mathrm{t}_{1}-\mathrm{t}_{2}$, saklar $\mathrm{S} 1$ on dan $\mathrm{S} 2$ off ditunjukan pada Gambar 5. Sumber DC $\mathrm{V}_{\text {in }}$ menyalurkan energi ke induktor kopel $\mathrm{L}_{\mathrm{Np}}, \mathrm{L}_{\mathrm{lk}}$ dan $\mathrm{Lm}$ ke $\mathrm{S} 1$ kemudian ke $\mathrm{C}_{1}$, sehingga tegangan $\mathrm{L}_{\mathrm{lk}}$ dan Lm mengirimkan ke $\mathrm{C}_{1}$ menjadi $\mathrm{V}_{\mathrm{C} 1}$ dan kembali ke $\mathrm{VL}_{\mathrm{Np}}$. Pada saat yang sama tegangan $\mathrm{V}_{\text {in }}$, induktor $\mathrm{L}_{\mathrm{m}}, \mathrm{L}_{\mathrm{lk}}$ dan $\mathrm{L}_{\mathrm{Np}}$, kapasitor $\mathrm{C}_{2}$ terhubung seri untuk menyalurkan energi ke induktor $\mathrm{L}_{\mathrm{o}}$, kapasitor $\mathrm{C}_{\mathrm{o}}$, dan beban $\mathrm{R}$. Karena tegangan seri melewati $C_{2}$ maka membuat dioda $D_{1}$ menjadi terbias mundur dan $\mathrm{VL}_{\mathrm{Ns}}$ tidak teraliri tegangan, sehingga membuat tegangan pada $\mathrm{L}_{\mathrm{o}}$ menjadi bernilai positif.

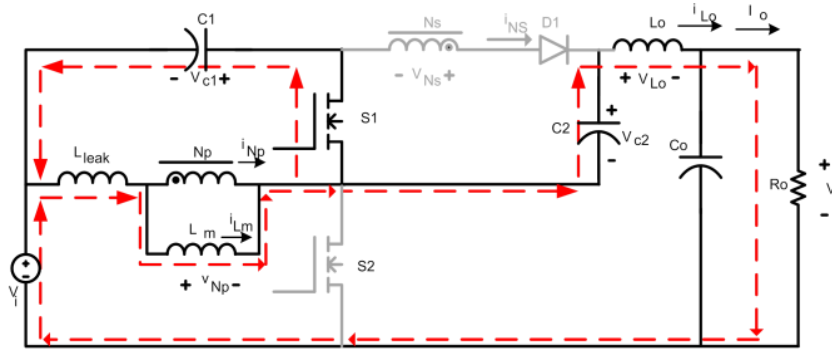

Gambar 5. Mode 2 Operasi 2( $\left.\mathrm{t}_{1}-\mathrm{t}_{2}\right)$

\section{Analisis Persamaan Rasio Konverter}

Induktor kopel dimodelkan sebagai transformator ideal dengan induktor magnetisasi $\mathrm{L}_{\mathrm{m}}$ dan induktor bocor $\mathrm{L}_{\mathrm{lk}}$ disisi primer, perbandingan belitan $(\mathrm{N})$ dan kopling koefisien dari induktor kopel didefinisikan sebagai berikut :

$N=\frac{N_{s}}{N_{p}}$
$k=\frac{L_{m}}{L_{l k}+L_{m}}=\frac{L_{m}}{L_{p}}$

Dimana $\mathrm{n}_{1}$ dan $\mathrm{n}_{2}$ adalah jumlah belitan primer dan sekunder induktor kopel.

Pada gambar 4, saklar S1 off dan S2 on, Sumber DC $\mathrm{V}_{\text {in }}$ menyalurkan energi ke induktor $\mathrm{L}_{\mathrm{Np}}$ dan $\mathrm{L}_{\mathrm{m}}$ kemudian ke $\mathrm{S} 2$. 
Sehingga membuat $\mathrm{Np}$ terinduksi dan persamaan tegangan yang melewati $\mathrm{V}_{\mathrm{Np}}$ dan $\mathrm{V}_{\mathrm{Ns}}$ dapat di tulis sebagai berikut :

$V_{N p}=L_{M} \times\left(\frac{N_{2}}{N_{1}}\right) \times V_{i}=k V_{i}$

$V_{N s}=V_{N p} \times \frac{N_{S}}{N_{p}}=k V_{i} \times \frac{N_{S}}{N_{p}}$

Pada saat yang sama tegangan pada kapasitor $\mathrm{C}_{2}$ dan $\mathrm{L}_{\mathrm{o}}$ dapat di tulis dengan persamaan sebagai berikut :

$V_{C 2}=V_{C 2}=V_{i}+V_{C 1}+V_{N S}=V_{i}+V_{C 1}+k V_{i} \times \frac{N_{S}}{N_{P}}$

$V_{L o}=V_{C 2}-V_{o}$

Pada mode I, gambar 3 saklar S1 on dan S2 off, tegangan yang melewati induktor $\mathrm{L}_{\mathrm{o}}$ dan kapasitor $\mathrm{C}_{1}$ dapat ditulis sebagai berikut :

$V_{N p}=-k V_{C 1}$

$V_{L o}=V_{i}+V_{C 1}+V_{C 2}-V_{o}$

Dengan mengaplikasikan prinsip induktor volt-second balance pada kedua induktor $\mathrm{L}_{\mathrm{m}}$ dan $\mathrm{L}_{\mathrm{lk}}$ pada satu periode pensaklaran didapat persamaan sebagai berikut :

$\int_{0}^{D T s} V_{L m(o n)} d t+\int_{D T s}^{T} V_{L m(0 f f)} d t=0$

$\mathrm{DT} \mathrm{kVin}+(1-\mathrm{D}) \mathrm{T} V_{\text {Lm(off })}=0$

$V_{C 1}=\frac{D}{1-D} \times V_{i}$

Dengan mengaplikasikan prinsip yang sama pada induktor $\mathrm{L}_{\mathrm{o}}$ didapatkan persamaan sebagai berikut :

$\int_{0}^{D T s} V_{L o(o n)} d t+\int_{D T s}^{T} V_{L o(0 f f)} d t=0$

$\left(V_{C 2}-V_{o}\right) \times D+\left(V_{i}+V_{C 1}+V_{C 2}-V_{o}\right) \times(1-D)=0$

Kemudian dilakukan substitusi persamaan (5) dan (11) ke persamaan (13) maka diperoleh

$M=\frac{V_{o}}{V_{i}}=\frac{2-D}{1-D}+k \frac{N_{S}}{N_{P}}$

Induktor magnetisasi $\mathrm{L}_{\mathrm{m}}$ memiliki nilai yang jauh lebih besar dibandingkan dengan nilai $\mathrm{L}_{\mathrm{k}}$, sehingga nilai $\mathrm{k}$ mendekati 1. Dengan menganggap bahwa nilai k sama dengan 1 (induktor kopel ideal), maka persamaan (14) dapat ditulis menjadi :

$M=\frac{V_{o}}{V_{i}}=\frac{2-D}{1-D}+\frac{N_{S}}{N_{P}}$

Nilai induktor magnetisasi $\mathrm{L}_{\mathrm{m}}$ dan induktor output $\mathrm{L}_{\mathrm{o}}$ dapat ditentukan dengan menggunakan asumsi yang telah ditentukan, yaitu semua komponen dianggap ideal.

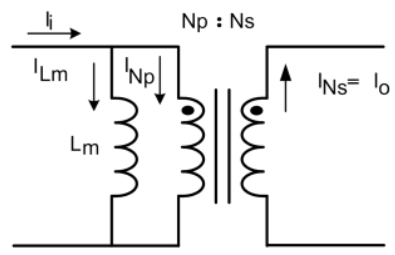

Gambar 6. Model Rangkaian Equevalen Dari Kopel Induktor

Dengan asumsi hukum kirchoff dalam rangkaian gambar 6 , maka

$I_{\text {in }}=I_{L m}+I_{N P}$

$I_{L m}=I_{i}-I_{N P}$

$I_{N p}=\frac{N_{s}}{N_{P}} \times I_{N s}$

$I_{o}=\frac{V_{O}}{R_{O}}$

Dan dengan asumsi besar daya input sama dengan besar daya output, maka

$P_{\text {in }}=P_{\text {out }}$

$I_{i}=\frac{V_{o}^{2}}{R_{o} \times V_{i}}$

Dan substitusikan persamaan (15) ke dalam persamaan (21) diperoleh

$I_{i}=\left(\frac{2-D}{1-D}+\frac{N_{S}}{N_{p}}\right) \times \frac{V_{O}}{R_{O}}$

Substitusi persamaan (22) ke persamaan (17) diperoleh

$I_{L m}=I_{i}-I_{N P}$

$I_{L m}=\frac{2-D}{1-D} \times I_{o}$

Nilai maksimum dan minimum arus induktor $\mathrm{L}_{\mathrm{m}}$ dapat ditentukan dengan menggunakan nilai rata-rata dan nilai perubahan arusnya, sehingga di peroleh.

$I_{L m, \text { max }}=I_{L m}+\frac{\Delta I_{L m}}{2}$
$I_{L m, \text { min }}=I_{L m}-\frac{\Delta I_{L m}}{2}$

Dimana

$L=L \frac{d i}{d t}$

$\Delta I_{L m}=\frac{V_{i}}{L_{m}} \times D T_{s}$

Sehingga, setelah dilakukan substitusi persamaan (25) dan (29) ke persamaan (26) dan (27), maka diperoleh

$I_{L m, \text { max }}=\frac{2-D}{1-D} \times I_{O}+\frac{V_{i} D T_{S}}{2 L_{m}}$
$I_{L m, \text { min }}=\frac{2-D}{1-D} \times I_{O}-\frac{V_{i} D T_{S}}{2 L_{m}}$

Syarat konverter beropersai secara Contiunous Conduction Mode (CCM) adalah arus induktornya harus selalu lebih dari nol. Sehingga, berdasarkan persamaan (31), nilai induktor $\mathrm{L}_{\mathrm{m}}$ minimal agar konverter bekerja secara $C C M$ adalah

$0<I_{L m, \min }$ 
$L_{m}>\frac{V_{i} D T_{S}}{2 \times\left(\frac{2-D}{1-D} \times I_{o}\right)}$

Dengan menggunakan prinsip hukum kirchoff, maka nilai induktor magnetisasi $\mathrm{L}_{\mathrm{o}}$ dapat ditentukan dari gambar 6 sebagai berikut :

$I_{N s}=I_{o}=I_{L o}=\frac{V_{o}}{R_{o}}$

Sehingga nilai maksimum dan minimum arus induktor $\mathrm{L}_{\mathrm{m}}$ dapat ditentukan dengan menggunakan nilai rata-rata dan nilai perubahan arusnya.

$I_{L o, \max }=I_{L o}+\frac{\Delta I_{L O}}{2}$

$I_{L o, \min }=I_{L o}-\frac{\Delta I_{L O}^{2}}{2}$

Dimana

$L=L \frac{d i}{d t}$

$\Delta I_{L o}=\frac{V_{L o}}{L_{o}} \times D T_{S}$

Dengan substitusikan (19), (21), (22) kedalam persamaan (38), maka diperoleh

$\Delta I_{L o}=\frac{V_{L o} D T_{S}}{L_{o}}=\frac{\left(V_{i}+V_{C 1}+V_{C 2}-V_{o}\right) \times(1-D) T S}{L_{o}}$

Sehingga, setelah dilakukan substitusi persamaan (34) dan (39) ke persamaan (35) dan (36), maka diperoleh

$I_{L o, \max }=\frac{V_{o}}{R_{o}}+\frac{V_{L o} D T_{S}}{2 L_{o}}$

$I_{L o, \min }=\frac{V_{o}}{R_{o}}-\frac{V_{L o} D T_{S}}{2 L_{o}}$

Syarat konverter beropersai secara Contiunous Conduction Mode $(C C M)$ adalah arus induktornya harus selalu lebih dari nol. Sehingga, berdasarkan persamaan (41), nilai induktor $L_{o}$ minimal agar konverter bekerja secara $C C M$ adalah

$0<I_{L o, \min }$

$L_{o}>\frac{V_{L o} D T_{S}}{2 \times I_{L o}}$

Sedangkan untuk mendapatkan persamaan pada kapasitor $\mathrm{C}_{1}$ dapat diperoleh dengan menggunakan persamaan (44);

$C_{1} \geq \frac{i_{C 1} \times \Delta t}{\Delta V_{C 1}}=\frac{\left(I_{i, \text { rated }}-I_{o, \text { rated }}\right) \times(1-D) T_{S}}{\Delta V_{C 1} \times V_{C 1}}$

Kapasitor $\mathrm{C}_{2}$ dapat diperleh dengan menggunakan persamaan (45);

$C_{2} \geq \frac{i_{C 2} \times \Delta t}{\Delta V_{C 2}}=\frac{I_{L o, r a t e d} \times(1-D) T_{S}}{\Delta V_{C 2} \times V_{C 2}}$

Dan kapasitor $\mathrm{C}_{3}$ dapat diperoleh dengan menggunakan persamaan (46) dan (47) :

$E S R \leq \frac{\Delta_{V o}}{\Delta_{i L o}}=\frac{\Delta_{V o} \times V_{o}}{\Delta i_{L o}}$
$C_{0} \geq \frac{65 \mu}{E S R}$

\section{DESAIN, SIMULASI DAN IMPLEMENTASI}

\section{A. Desain}

Desain konverter dilakukan untuk mementukan parameter rangkaian dengan menghitung sehingga mempermudah proses implementasi pada penelitian yang akan dilakukan. Table 1 . Merupakan parameter awal yang digunakan sebagai acuan dalam proses perancangan konverter.

Penentuan Rasio Konversi dan Duty Cycle menggunakan persamaan (15), besar rasio konversi (M) dan duty cycle (D) yang dibutuhkan konverter untuk menaikkan tegangan dengan kopling koefisien $=1$, dapat ditentukan sebagai berikut :

$M=\frac{V_{o}}{V_{i}}=\frac{320}{30}=10.66$

$D=\frac{\left(\frac{320}{30}\right)-\left(\frac{6}{1}\right)-2}{\left(\frac{320}{30}\right)-\left(\frac{6}{1}\right)-1}=0.72$

Pada saat tegangan masukkan maksimum $\left(\mathrm{V}_{\text {in }}=35 \mathrm{~V}\right)$, besar rasio konversi dan duty cycle konverter adalah

$M=\frac{V_{o}}{V_{i}}=\frac{320}{35}=9.14$

$D=\frac{\left(\frac{320}{35}\right)-\left(\frac{6}{1}\right)-2}{\left(\frac{320}{35}\right)-\left(\frac{6}{1}\right)-1}=0.53$

Kemudian sesuai dengan spesifikasi alat yang akan dibuat pada Tabel 1, maka besar beban $\mathrm{R}$ akan digunakan adalah sebagai berikut :

$R_{\text {out }, \text { max }}=\frac{V^{2} \text { out }}{P_{\text {out }, \text { max }}}=\frac{320^{2}}{100}=1024 \Omega$

Konverter ini dirancang untuk selalu beroperasi secara CCM (Continous Conduction Mode). Sehingga perlu diketahui nilai batas minimum arus yang mengalir pada induktor $\mathrm{L}_{\mathrm{lk}}$ dan $\mathrm{L}_{\mathrm{m}}$ kontinus:

$R_{\text {out }, \text { min }}=\frac{V^{2} \text { out } \text { min }}{P_{\text {out } \text { min }}}=\frac{320^{2}}{10}=10240 \Omega$

$I_{L m, \min }=\frac{2-D}{1-D} \times \frac{V_{0}}{R_{0, \min }}==\frac{2-0.72}{1-0.72} \times \frac{320}{10240}=0.143 \mathrm{~A}$

Setelah memperoleh nilai arus $\mathrm{L}_{\mathrm{m}}$ minimum, maka nilai $\mathrm{L}_{\mathrm{m}}$ yang diperoleh :

Tabel 1.

Spesifikasi Awal Perancangan Konverter

\begin{tabular}{lc}
\hline \hline \multicolumn{1}{c}{ Parameter } & Nilai Besaran \\
\hline Tegangan Masukkan $\left(V_{\text {in }}\right)$ & $30-35 \mathrm{Volt}$ \\
Tegangan Keluaran $\left(V_{o}\right)$ & $320 \mathrm{Volt}$ \\
Frekuensi Pensaklaran $(f s)$ & $100 \mathrm{kHz}$ \\
Daya Masukkan $\left(P_{i n}\right)$ & $100 \mathrm{Watt}$ \\
Daya Keluaran, Max $\left(P_{o, \max }\right)$ & $100 \mathrm{Watt}$ \\
Daya Keluaran, Min $\left(P_{o, \min }\right)$ & $10 \mathrm{Watt}$ \\
Perbandingan Belitan & $1: 6$ \\
Riak Tegangan $C_{l}\left(\Delta C_{l}\right)$ & $1 \%$ \\
Riak Tegangan $C_{2}\left(\Delta C_{2}\right)$ & $0.1 \%$ \\
Riak Tegangan $C_{o}\left(\Delta C_{o}\right)$ & $0.1 \%$ \\
Ripple Arus $L_{o}\left(\Delta L_{o}\right)$ & $20 \%$ \\
\hline \hline
\end{tabular}


$L_{m} \geq \frac{V_{i} D T_{S}}{\Delta i_{L m}}=\frac{V_{i} D T_{S}}{2 \times I_{L m, \min }}=\frac{30 \times 0.72 \times 10 \mu}{2 \times 0.143}=755 \mu \mathrm{H}$

Pada perancangan untuk menentukan nilai induktor berdasarkan persamaan (43) dengan ripple arus maksimum di tetukan sebesar 20\%, sehingga diperoleh nilai $\mathrm{L}_{\mathrm{o}}$ sebagai berikut :

$L_{o} \geq \frac{v_{L o} \Delta t}{\Delta i_{L o}}=\frac{\left(V_{i}+V_{i} \times \frac{D}{1-D}+V_{i}+V_{i} \times \frac{D}{1-D}+V_{i} \times \frac{N_{S}}{N_{p}}-V_{0}\right)(1-D) T_{S}}{20 \% \times I_{\text {Lo, rated }} \times 2}$

$L_{o} \geq \frac{\left(30+30 \times \frac{0.72}{0.28}+30+30 \times \frac{0.72}{0.28}+30 \times 6-320\right)(0.28) 10 \mu}{20 \% \times 0.0 .3215 \times 2}$

$L_{o} \geq 1.664 m H$

Nilai kapasitor $\mathrm{C}_{1}$ dihitung menggunakan persamaan (44). Dimana ripple tegangan ditentukan sebesar $1 \%$ sehingga diperoleh nilai sebagai berikut :

$V_{C 1}=V_{i} \times \frac{D}{1-D}=30 \times \frac{0.72}{1-0.72}=77.14 \mathrm{~V}$

Untuk mencari nilai kapasitansi dari $\mathrm{C}_{1}$, maka dapat diperoleh:

$C_{1} \geq \frac{i_{C 1} \Delta t}{\Delta_{v c 1}}=\frac{\left(I_{i, \text { rated }} I_{o, \text { rated }}\right)(1-D) T_{S}}{0.01 \times V_{C 1}}$

$C_{1} \geq \frac{(3.33-0.3125)(1-0.72) 10 \mu}{0.01 \times 30}=10.95 \mu F$

Nilai kapasitor $\mathrm{C}_{2}$ dihitung menggunakan persamaan (45). Dimana ripple tegangan ditentukan sebesar $0.1 \%$ sehingga diperoleh nilai sebagai berikut :

$V_{C 2}=V_{i}+V_{C 1}+V_{i} \times \frac{N_{S}}{N_{p}}$

$V_{C 2}=30+30 \times \frac{0.72}{1-0.72}+30 \times \frac{6}{1}=237.14$ Volt

Untuk mencari nilai kapasitansi dari $\mathrm{V}_{\mathrm{C} 2}$, maka dapat diperoleh:

$C_{2} \geq \frac{i_{C 2} \Delta t}{\Delta_{v c 2}}=\frac{0.3125(1-0.72) 10 \mu}{0.01 \times 237.14}=0.3689 \mu F$

Nilai kapasitor filter $\mathrm{C}_{\mathrm{o}}$ dihitung menggunakan persamaan (46) dan persamaan (47). Dimana ripple tegangan ditentukan sebesar $0.1 \%$ sehingga diperoleh nilai sebagai berikut :

$E S R \leq \frac{\Delta V_{o}}{\Delta i_{L o}}=\frac{0.001 \times V_{o}}{20 \% \times I_{\text {Lo, rated }} \times 2}=\frac{0.001 \times 320}{20 \% \times 0.3125 \times 2} \approx 2,56 \Omega$

$C_{3} \geq \frac{65 \mu}{E S R}=\frac{65 \mu}{2,56} \approx 25,39 \mu F$

Karena nilai kapasitor tidak tersedia dipasaran maka untuk mempermudah simulasi dan implementasi digunakan nilai kapasitor yang tersedia dipasaran dan dipilih nilai sedikit lebih besar dibanding hasil perhitungan yaitu $\mathrm{C}_{1}=22 \mu \mathrm{F} / 160 \mathrm{v}, \mathrm{C}_{2}=$ $10 \mu \mathrm{F} / 250 \mathrm{v}, \mathrm{C}_{3}=33 \mu \mathrm{F} / 450 \mathrm{v}$.

Dalam perancangan kopel induktor, langkah yang dilakukan adalah menghitung arus yang akan melalui kopel induktor dihitung melalui persamaan dibawah.

$I_{\text {in }}=\frac{P_{\text {in }}}{V_{\text {in }}}=\frac{100}{30}=3.33 \mathrm{~A}$
Pengukuran induktansi bocor dilakukan dengan cara melakukan mengubungkan singkatkan belitan sekunder [5]. Setelah dilakukan pengulungan dan pengukuran kebocoran induktasi pada kopel induktor tahap selanjutnya melakukan perhitungan nilai induktasi magnetisasi dengan data hasil pembuatan kopel induktor.

$\begin{array}{ll}\mathrm{L}_{11}=1053,2 \mu \mathrm{H} & \mathrm{N}_{1}=1 \\ \mathrm{~L}_{22}=27730 \mu \mathrm{H} & \mathrm{N}_{2}=6 \\ \mathrm{~L}_{\text {leak12 }}=8,036 \mu \mathrm{H} & \\ L_{m}=\frac{N_{1}}{N_{2}} \times \sqrt{\left(L_{11} \times L_{22}\right)-\left(L_{\text {leak } 12}-L_{22}\right)} \\ L_{m}=\frac{1}{6} \times \sqrt{(1053,2 \mu H \times 27730 m H)-(8,036 \mu H-27730 \mu H)} \\ L_{m}=897,255 \mu \mathrm{H}\end{array}$

\section{B. Implementasi}

Implementasi dilakukan untuk mengetahui kinerja dari konverter DC-DC kombinasi konverter KY dengan konverter Buck-Boost berdasarkan desain dan simulasi yang telah dilakukan

Tabel 2.

Kapasitas Komponen Implementasi

\begin{tabular}{|c|c|c|}
\hline Komponen & Nilai Besaran & Unit \\
\hline \multicolumn{3}{|l|}{ Trafo Frekuensi tinggi } \\
\hline Magnetisasi Induktor $L_{m}$ & $897,255 \mu \mathrm{H}$ & 1 \\
\hline Kebocoran Induktor $L_{l k g}$ & $8,036 \mu \mathrm{H}$ & \\
\hline Output induktor $\quad L_{o}$ & $1.664 \mathrm{mH}$ & 1 \\
\hline Kapasitor & $22 / 160 v \mu F$ & 1 \\
\hline Charger kapasitor & $10 / 250 \mathrm{v} \mu \mathrm{F}$ & 1 \\
\hline Ouput kapasitor & $33 / 450 v \mu F$ & 1 \\
\hline Saklar $S_{1}$ dan $S_{2}$ & IRFP460 20A/500V & 2 \\
\hline Diode MUR1560 & $600 \mathrm{~V} / 15 \mathrm{~A} /$ Ultra fast recovery & 1 \\
\hline Kendali Pensaklaran & Mikrokontroler Arduino Uno & 1 \\
\hline FOD3182 & $200 \mathrm{kHz}$ & 2 \\
\hline
\end{tabular}

Sesuai Sesuai dengan komponen pada table 2. Gambar 4 menunjukkan hasil implementasi penelitain dari kombinasi konverter KY dan konverter buck-boost.

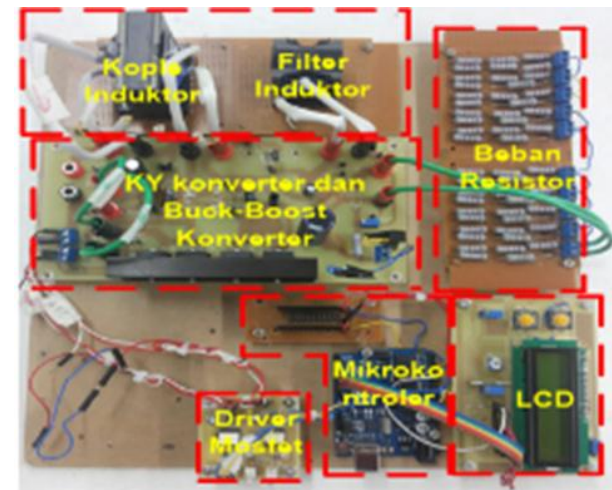

Gambar 8. Implementasi konverter kombinasi konverter KY dan BuckBoost konverter

\section{PENGUJIAN}

\section{A. Pengujian Bentuk Gelombang Pensaklaran}

Pengujian sinyal PWM dan pensaklaran bertujuan untuk mengetahui sinyal pensaklaran yang telah dibuat sudah sesuai dengan peracangan dan simulasi. Gambar 9 menunjukan pengujian sinyal pensaklaran yang dilakukan mengunakan 
dutycycle 50\%, sehingga besar periode gelombang PWM dan pensaklaran konverter adalah 10us.

\section{B. Pengujian Arus Induktor dan Tegangan Kapasitor}

Dari gambar 9 dapat diketahui bahwa $\mathrm{L}_{\mathrm{m}}$ dapat bekerja CCCM. Besar arus yang mengalir pada implementasi induktor sisi primer $\mathrm{IL}_{\mathrm{m}}+\mathrm{IL}_{\mathrm{Np}}=5,20 \mathrm{~A}$, arus sisi sekunder $\mathrm{IL}_{\mathrm{Ns}}=2,7 \mathrm{~A}$, sedangkan arus indukor $\mathrm{L}_{\mathrm{o}}=1,24 \mathrm{~A}$. Nilai arus saat implemetasi lebih besar dibandingkan dengan simulasi hal ini terjadi karena setiap komponen yang digunakan memiliki efek ketidak idealan. Besar arus hasil simulasi adalah induktor sisi primer $\mathrm{IL}_{\mathrm{m}}+\mathrm{IL}_{\mathrm{Np}}=4,8 \mathrm{~A}$, arus sisi sekunder $\mathrm{IL}_{\mathrm{Ns}}=0,782 \mathrm{~A}$, sedangkan arus indukor $\mathrm{L}_{\mathrm{o}}=0,089 \mathrm{~A}$.

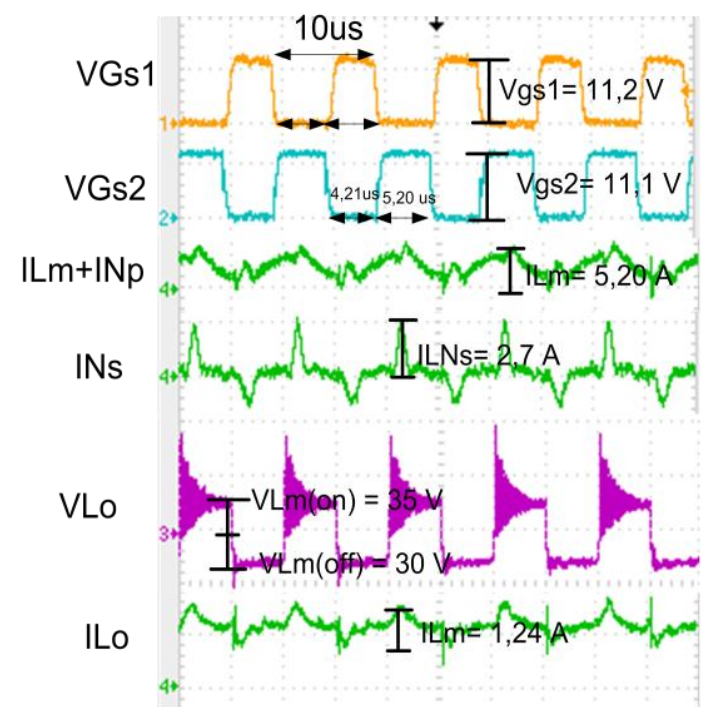

Gambar 9. Bentuk Gelombang Arus Induktor dan Tegangan pada Induktor

\section{Pengujian Rasio Konversi}

Rasio konversi dilakukan untuk mengetahui kemampuan konverter dalam menaikkan tegangan masukkan ke tegangan yang lebih tinggi sering dengan meningkatnya perubahan dutycycle. Dengan memberikan tegangan kostan $30 \mathrm{~V}$ dengan beban yang digunakan adalah resistor sebesar $1057 \Omega$.

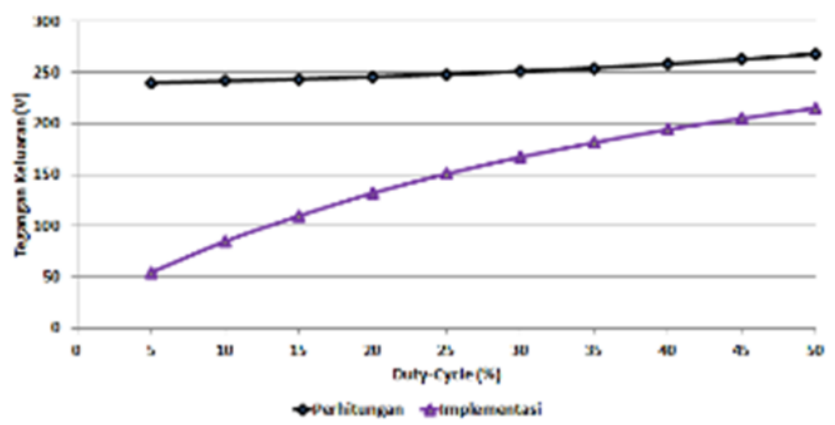

Gambar 10. Grafik Rasio Konversi Tegangan Terhadap Dutycycle

Kemudian dutycycle dinaikkan dari 5\% sampai $50 \%$. Dutycycle hanya dinaikkan sampai 50\% karena ketika lebih dari 50\% kopel induktor bunyi sehingga mengakibatkan kopel induktor terjadi saturasi. Hal ini terjadi disebabkan kemampuan bahan ferrite yang digunakan sudah tidak mampu lagi untuk menahan arus yang melewati kawat sehingga membuat terjadinya saturasi pada trafo ferrite.
Dari gambar 10, bahwa hasil perhitungan dan implementasi terjadi perbedaan ini dikarenakan adanya drop tegangan pada kebocoran induktansi yang mana nilainya dipengaruhi oleh dutycycle. Jika dutycycle kecil maka nilai drop tegangan pada sisi kebocoran induktansi besar. Sedangkan ketika dutycycle semakin tinggi maka drop tegangan disisi kebocoran induktansi perlahan berkurang.

\section{Pengujian Efisiensi}

Pengujian efisiensi dilakukan dengan menjaga tegangan masukkan dan tegangan keluaran konverter konstan. Sedangan beban diubah-ubah sehingga dihasilkan daya keluaran yang berbeda. Dari gambar 11, dapat diketahui bahwa efisiensi pada daya 70 watt pada tegangan masukkan $30 \mathrm{~V}$ bernilai lebih dari $80 \%$. Seiring dengan penurunan daya keluaran konverter, efisiensi juga semakin menurun. Dari pengujian yang dilakukan efisiensi maksimum terdapat pada beban $70 \%$ sampai $90 \%$.

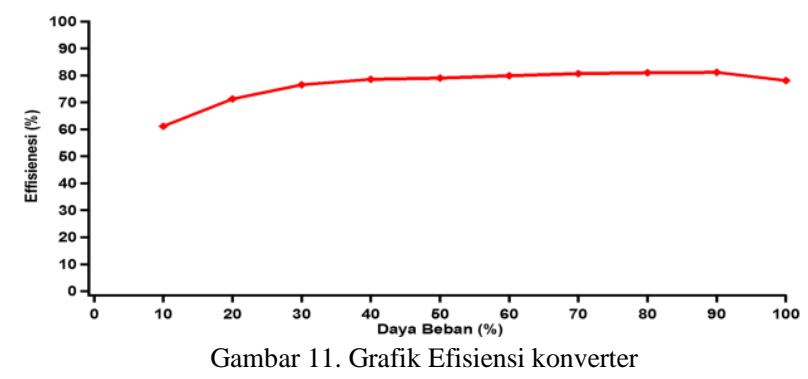

\section{E. Pengujian Respon kontrol Tegangan}

Pengujian ini dilakukan untuk mengetahui apakah kontrol close loop yang telah di buat dapat bekerja dengan baik pada konverter yang telah diimplementasikan. Pengendalian kontrol close loop menggunakan kontrol PI (Proporsional Integral) untuk mengetahui respon tegangan keluaran dari kontrol dutycycle terhadap perubahan tegangan masukkan yang berubah. Pada pengaplikasian kontrol PI menggunaan metode trial and error untuk memperoleh respon yang baik. Dari gambar 13 menunjukkan tegangan keluaran tetap stabil walaupun tegangan masukkan berubah.

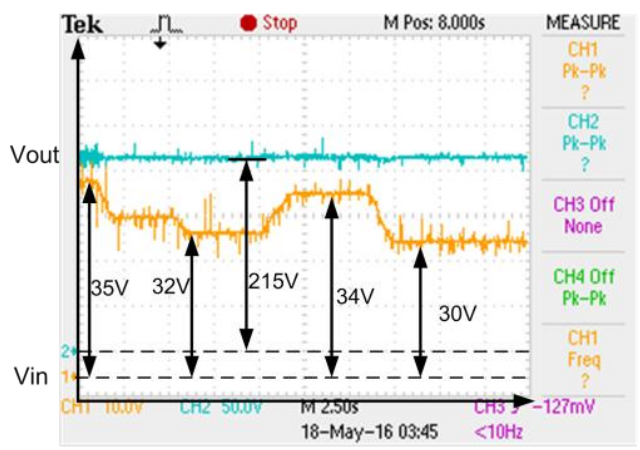

Gambar 13. Gelombang tegangan keluaran akibat perubahan tegangan

\section{F. Pengujian dengan Modul Fotovoltaik}

Pengujian dilakukan dengan menggunakan modul fotovoltaik untuk mengetahui bahwa tegangan keluaran dari konverter dapat dijaga konstan saat sumber tegangan masukkan yang digunakan berubah dan untuk mengetahui apakah sistem kendali PI yang telah digunakan dapat bekerja 
dengan baik ketika terjadi perubahan tegangan masukkan akibat irradiasi dari fotovoltaik.

Pengujian dilakukan mulai pagi hari jam 08.00 sampai sore hari jam 15.30 dimana sinar matahari masih cukup menghasilkan energi listrik yang diperlukan. Pengujian dilakukan menggunakan beban tahanan resistor $1263 \Omega$ sehingga daya yang dihasilkan $\pm 36,59$ watt ketika besar tegangan keluaran 215 volt.

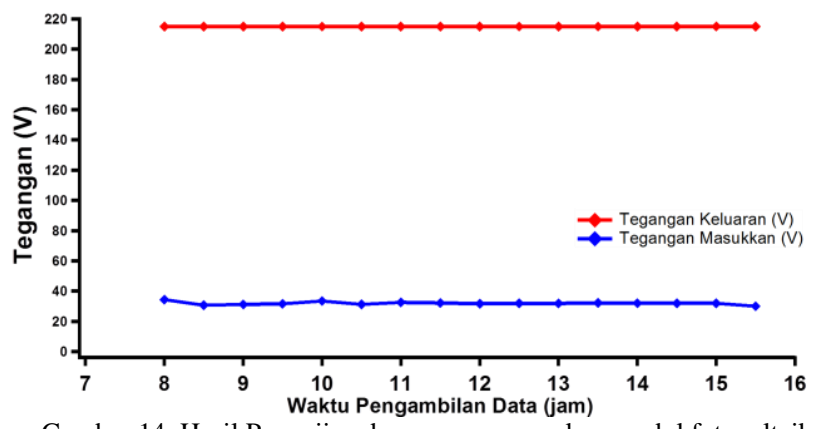

Gambar 14. Hasil Pengujian dengan menggunakan modul fotovoltaik

\section{KESIMPULAN/RINGKASAN}

Dari hasil simulasi dan implementasi konverter dapat disimpulkan bahwa implementasi kombinasi KY converter dan Buck-Boost converter didapatkan rasio konversi hingga 7,16 kali. Respon waktu pensakelaran pada konverter sangat cepat untuk mencapai kondisi steady state sebesar 0,1s. dengan konverter memiliki efisiensi hingga $81,18 \%$ saat daya 90\%. Tegangan keluaran dapat dijaga konstan saat tegangan masukkan berubah-ubah.

\section{DAFTAR PUSTAKA}

[1] Yongchang, Yu, dan Yao Chaunan, 2012. "Implementasi Of A MPPT Controller Based On AVR Meega16 For Photovoltaic Systems". ELSIVIER, 2012.

[2] Oshaba, A.S, dkk. "MPPT Control Design Of PV System Supplied SRM Using BAT Search Algorithm". ELSEVIER, Sustainable Energy, Grid and Networks 2 (2015) 51-60.

[3] Ashari, Mochammad, "Sistem Konverter DC, Desain Rangkaian Elektronika Daya”. ITS Press. 2012.

[4] Hwu, K.I, dan W. Z. Jiang, "Voltage Gain Enhancement for a Step-Up Konverter constructed by KY and Buck-Boost Konverter". IEEE Transaction On Industrial Electronic, Vol. 61, No. 04, April 2014.

[5] Hesterman, Bryce. "Analysis and modeling of Mgnetic Cooupling".Denver Chapter, IEEE Power Electronics Socienty. Colorado. 2007. 